\title{
Review
}

\section{Implant survival rates after maxillary sinus augmentation}

\author{
Del Fabbro M, Rosano G, Taschieri S. Implant survival rates after maxillary sinus \\ augmentation. Eur J Oral Sci 2008; 116: 497-506. (C) 2008 The Authors. Journal \\ compilation (C) 2008 Eur J Oral Sci
}

Implant therapy in the atrophic posterior maxilla becomes challenging in the presence of reduced maxillary bone height. Sinus augmentation can be performed for resolving this condition prior to implant placement. The aim of this article was therefore to evaluate implant survival rates in the grafted sinus taking into account the influence of the implant surface, graft material, and implant placement timing. A systematic review of the literature was performed. Articles retrieved from electronic databases were screened using specific inclusion criteria, and data extracted were divided according to: graft material (autogenous, non-autogenous, composite graft), implant surface (machined or textured), and implant placement (simultaneous with grafting or delayed). Fifty-nine articles were included. Survival rates for implants placed in grafts made of bone substitutes alone and grafts of composite material were slightly better than the survival rates for implants placed in 100\% autogenous grafts. Over $90 \%$ of implants associated with non-autogenous grafts had a textured surface. Textured surfaces achieved better outcomes compared with machined surfaces, and this was independent of the graft material. Simultaneous and delayed procedures had similar outcomes. It may be concluded that bone substitutes can be successfully used for sinus augmentation, reducing donor-site morbidity. Long-term studies are needed to confirm the performance of nonautogenous grafts. The use of implants with a textured surface may improve the outcome in any graft type.

\section{Massimo Del Fabbro, Gabriele Rosano, Silvio Taschieri}

Department of Technologies for Health, Denta Clinic, IRCCS Galeazzi Institute, University of Milan, Milan, Italy
Dr Massimo Del Fabbro, Università di Milano, Istituto Ortopedico Galeazzi, Via R. Galeazzi 4 20161 Milano, Italy

\section{Telefax: +39-02-50319960}

E-mail: massimo.delfabbro@unimi.it

Key words: bone substitutes; dental implants; maxillary sinus; sinus augmentation; systematic review

Accepted for publication August 2008
Placement of dental implants in the atrophic posterior maxilla is a challenging procedure in the presence of reduced maxillary bone height. Various clinical procedures and materials have been developed to overcome the problem of reduced bone volume. One of the most frequently used surgical interventions for obtaining adequate bone height prior to the placement of endosseous implants in the posterior maxilla is grafting to the floor of the maxillary sinus.

The sinus augmentation technique was first presented in the late 1970s in a series of lectures by TATUM (1), who then published a paper on the subject several years later. The first clinical study, in which autogenous cancellous bone from the lateral iliac crest was used as graft material, adopting a modified Caldwell-Luc procedure to approach the maxillary sinus, was published in 1980 (2). Since then, the sinus grafting technique has evolved over time and has been used by a growing number of clinicians, as shown by an increasing body of scientific literature. Several modifications to the original protocol have been carried out in order to improve the predictability of clinical outcomes and, at the same time, to reduce donor site morbidity caused by bone harvesting. In particular, various types of allografts, xenografts and alloplastic materials have been used as bone substitutes, alone or in combination with autogenous bone, to simplify the grafting phase and to minimize the patient's discomfort. While autogenous bone has long been considered the gold standard grafting material because of its osteoinductive and osteoconductive properties, alternative materials have, in general, no osteoinductive potential but are considered to provide a scaffold for optimal bone growth. The efficacy of the graft material in promoting graft maturation and providing optimal long-term support to endosseous implants is one of the most critical factors for the success of the sinus augmentation procedure. It seems therefore of interest to determine whether survival rates of implants differ when inserted in different graft materials

Another variable that may affect the process of bone formation around implants is the implant surface configuration. There is histologic and clinical evidence suggesting that a more favourable implant-bone interface is established on rough-surfaced implants compared with machined implants, especially in poor quality bone (3-8). It is therefore expected that, when inserted in grafted bone, the outcome of implants with a textured surface is better than those with a machined surface. It can also be 
appealing to investigate if it is the graft type or the implant surface (or a particular combination of these) that is mainly responsible for the treatment outcome in terms of the implant survival rate.

While the graft type and the implant characteristics can be chosen by the clinician, other variables of the sinus-augmentation procedure can be dictated by the specific clinical situation. For example, the choice of placing implants simultaneously to the grafting procedure or at a later stage can be influenced by the amount of residual crestal bone height. It has long been assumed that when the latter is less than $5 \mathrm{~mm}$ no adequate mechanical stability can be provided for the placement of endosseous implants. Primary implant stability is, in fact, considered mandatory for the success of the simultaneous procedure. However, more recent evidence challenges this concept, showing that when specific requirements are met success can be achieved when placing implants simultaneously to grafting, even if the residual crest bone height is limited to as little as $1 \mathrm{~mm}$ (9-11).

The primary objective of this systematic review was to assess the survival rate of implants placed in grafted maxillary sinus, based on clinical reports from 1986 to February 2007, and to determine if it is affected by the graft material, the implant surface texture, and the implant placement timing with respect to the grafting phase.

\section{Material and methods}

The search protocol used the following electronic databases: MEDLINE, with a time limit from 1986 to February 2007; EMBASE, with a time limit from 1988 to February 2007; and the Cochrane Oral Health Group Specialized Trials Register up to February 2007. Keywords such as 'maxillary sinus lift', 'sinus augmentation', 'sinus floor elevation', 'sinus graft', 'bone graft', 'endosseous implants', 'oral implants', and 'dental implants' were used, alone and in combination, for searching the databases. The search was limited to studies involving human subjects. Restrictions were not placed regarding type of study design and language usage.

A further hand search was performed on the major international journals in the field of implant dentistry and of oral and maxillofacial surgery from 1986 to 2007 (Clinical Oral Implants Research, Implant Dentistry, International Journal of Oral \& Maxillofacial Implants, International Journal of Oral \& Maxillofacial Surgery, International Journal of Periodontics \& Restorative Dentistry, Journal of Oral \& Maxillofacial Surgery, Journal of Periodontology). Finally, the bibliographies of the most relevant papers and review articles were examined to identify additional potentially relevant articles.

\section{Data extraction}

The titles and abstracts of the articles were screened by two authors (MDF, GR). Articles were selected according to the following inclusion criteria:(i) a lateral approach to the maxillary sinus was used, either the Caldwell-Luc technique, where the bone lid is entirely removed, or the lateral swing door technique, according to TATUM (1);(ii) at least 20 sinus augmentations were carried out;(iii) 'root-form' implants were used;(iv) fewer than $5 \%$ of the patients were lost during follow-up; (v) mean follow-up was no less than 12 months of implant loading, or the follow-up range exceeded 24 months; and (iv) the implant survival rate was clearly indicated or calculable from data reported in the paper.

Publications that did not meet the above inclusion criteria and those that were not dealing with original clinical cases (e.g. reviews, technical reports) were excluded. Multiple publications of the same pool of patients, when obvious, were also excluded from the database. When papers from the same group of authors were identified, with very similar databases of patients, materials, methods and outcomes, the authors were contacted to clarify whether the pool of patients was indeed the same. In case of multiple publications relative to consecutive phases of the same study only the most recent data (those with the longer follow-up) were considered.

The characteristics of included studies were independently assessed by two reviewers and the publications were grouped by study design [randomized controlled trials (RCT), controlled trials (CT), case series (CS) or retrospective studies (RS). The extracted data were grouped according to the following three parameters.

Type of graft material. This group was divided into three subgroups: (i) autogenous bone alone; (ii) autogenous bone in combination with bone substitutes; and (iii) bone substitutes alone.

Type of implant surface. This group was made up of two subgroups: (i) machined surface; and (ii) textured surface.

Implant placement timing. This group comprised two subgroups: (i) simultaneous technique; and (ii) delayed technique.

Each subgroup was further divided according to the mean follow-up duration: shorter than 36 months or equal to or longer than 36 months. The main outcome considered for the analysis was the implant survival rate.

\section{Results}

The search provided a total of 496 articles reporting maxillary sinus augmentation in combination with dental implant placement (Fig. 1). Of these, only 59 met all inclusion criteria for quantitative data analysis (Fig. 2). These articles (9, 11-67 and Testori T, unpublished data) were published in a 14-yr period from 1993 to February 2007 (Fig. 1) and reported data concerning more than 13,000 implants placed in the grafted sinuses of over 4,000 patients (Table 1). The overall implant survival rate from these studies was $93.62 \%$. Of the 59 articles examined, four were RCT $(6.8 \%), 11$ were CT $(18.6 \%), 23$ were CS $(39.0 \%)$, and 21 were RS $(35.6 \%)$.

The selected articles showed considerable differences in patients' residual crestal bone height, type of implants placed, graft materials used, success and survival criteria, and duration of follow-up. Moreover, there were differences in the study design and objectives, patient's inclusion and exclusion criteria, data reporting and methods of statistical analysis. All articles included in our analysis provided outcomes considering the implant as the unit of analysis. 


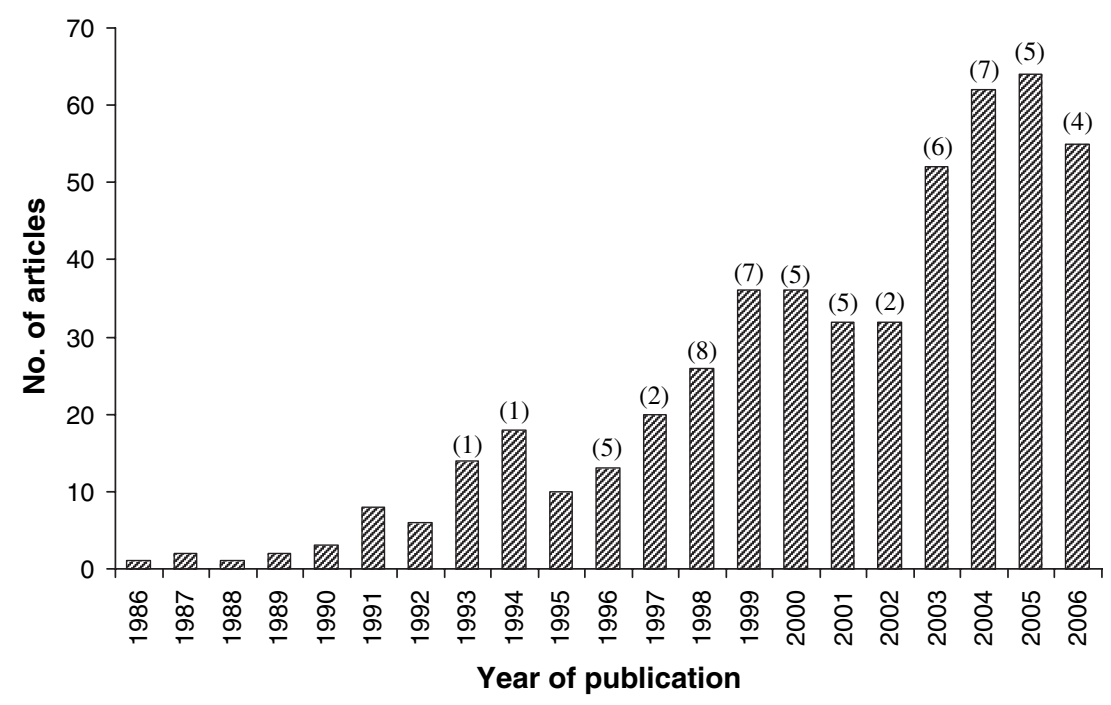

Fig. 1. Number of articles per year between 1986 and 2006 with respect to patients rehabilitated by means of implants placed in grafted maxillary sinus. The number of articles per year included in the present review is shown between parentheses above each bar.

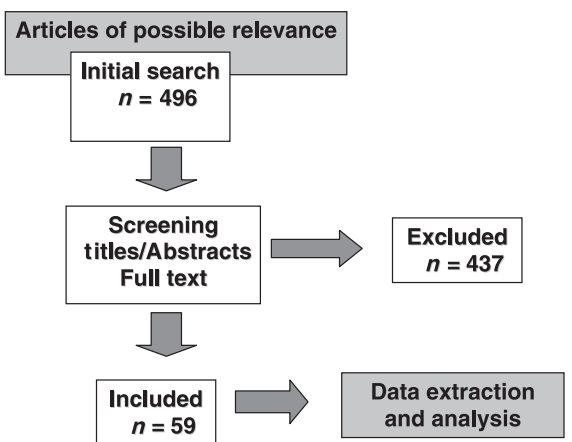

Fig. 2. Flow diagram showing the steps of the systematic review.

\section{Influence of graft material}

Data from all included studies, except eight papers (11, $37,41,54,59,60,64,66)$, could be allocated to at least one of the three subgroups considered in our analysis. Those eight studies, together accounting for 1,133 patients and 3,588 implants, used various types of graft materials but did not provide sufficient details to allow the data to be split according to the various subgroups in the present analysis.

In the subgroup using combination grafts, nine different graft materials were used in combination with autogenous bone: deproteinized bovine bone (Bio-Oss; Geistlich Pharma, Wolhusen, Switzerland), demineralized freeze-dried bone allograft (DFDBA; Musculoskeletal Foundation, Holmhoel, NJ, USA and Dentsply/ Friadent/Ceramed, Mannheim, Germany), hydroxyapatite (HA; Berkeley Advanced Biomaterials, Berkeley, CA, USA), OsteoGraf/N (Dentsply Friadent/Ceramed, Mannheim, Germany), Int-200 (Interpore International; Irving, CA, USA), $\beta$-TCP (Cerasorb $^{\circledR}$; Curasan AG, Kleinostheim, Germany). OsteoGraf/N + DFDBA, OsteoGraf/N + FDBA, BioPlant HTR (Replacement Therapy Materials, Mechelen, Belgium). (FDBA, freeze- dried bone allograft; Musculoskeletal Foundation, Holmhoel, NJ, USA and Dentsply/Friadent/Ceramed, Mannheim, Germany.)

In the subgroup using only bone substitutes, many different graft materials were used: Bio-Oss, DFDBA, HA, OsteoGraf/N + DFDBA, FDBA, OsteoGraf/N, $\beta$-TCP, calcium sulfate, HA + DFDBA, DFDBA + Bio-Oss, HA + Bio-Oss, DFDBA + Int-200, PRP (Platelet-Rich Plasma; SmartPrep, Harvest Technologies, Norwell, MA, USA) + Bio-Oss, bovine HA + fibrin glue, phycogenic material + fluorohydroxyapatite, and marine algae. In an RCT (60), the osteoinductive substance bone morphogenetic protein 2 (rhBMP-2; Wyeth/ Genetics Institute, Cambridge, MA, USA), embedded in a resorbable collagen sponge, was also used.

It was not the purpose of the present study to analyze separately the performance of each bone substitute or of any reported combination among them. Table 2 shows the overall implant survival rates according to the type of graft material used; the overall survival rate using $100 \%$ autogenous bone grafts was lower $(88.9 \%)$ with respect to combined grafts $(94.7 \%)$ and $100 \%$ bone substitutes $(96.1 \%)$. In the last two columns of Table 2, the data were further split according to type of implant surface. Unfortunately, to date, long-term reports on sinus floor elevation using bone substitute materials are, as a result of their relatively recent introduction, rather scarce compared with the numerous reports on the use of autogenous bone.

\section{Influence of implant surface}

Independently of the graft material, all implants with a machined surface displayed a mean survival rate of $86.3 \%$ (for 950 patients and 3,346 implants placed), while implants with a rough surface displayed a mean survival rate of $96.7 \%$ (for 2,544 patients and 8,303 implants placed). This comparison between smooth and rough implant surfaces did not take into consideration 
Del Fabbro et al.

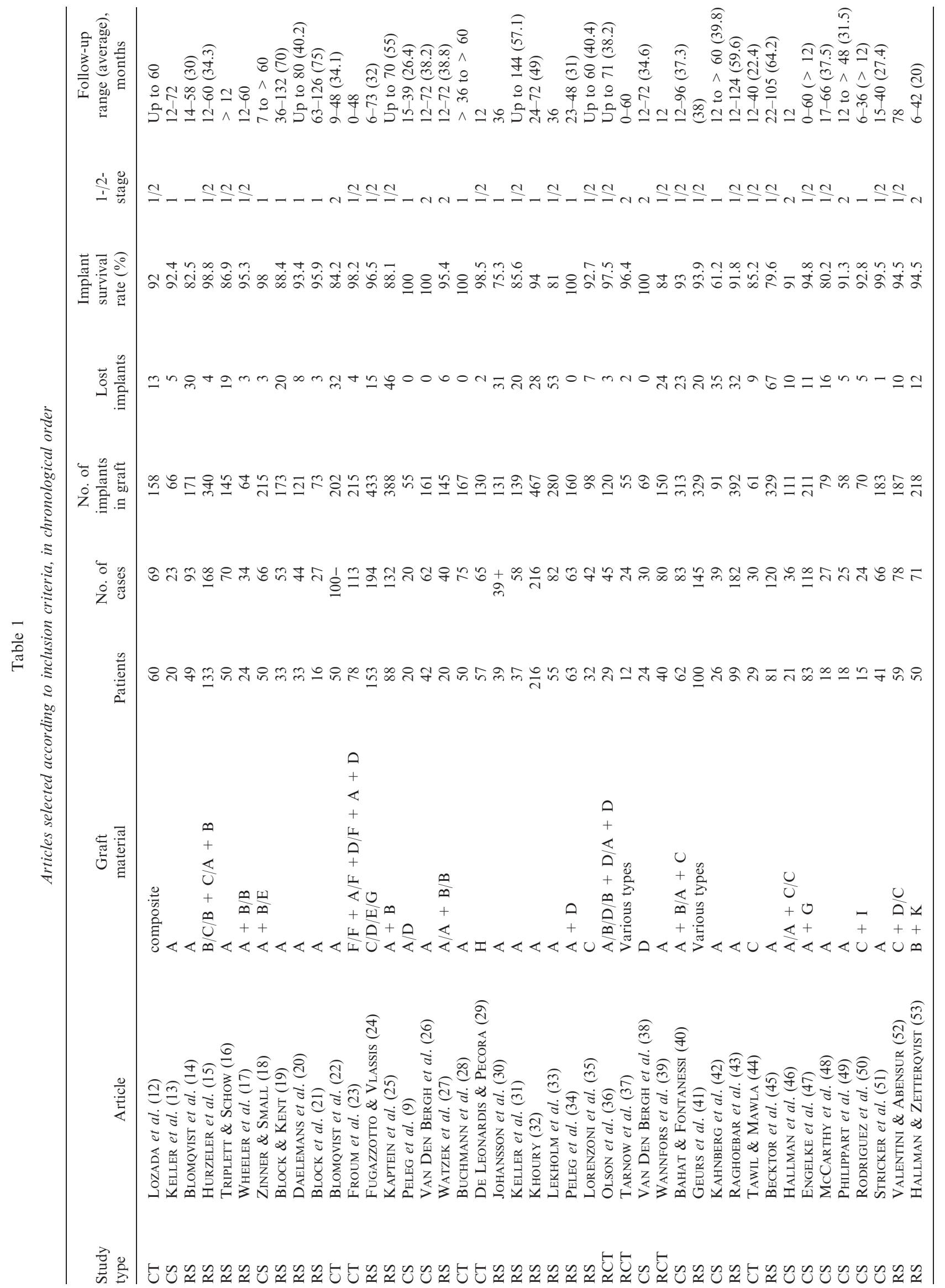




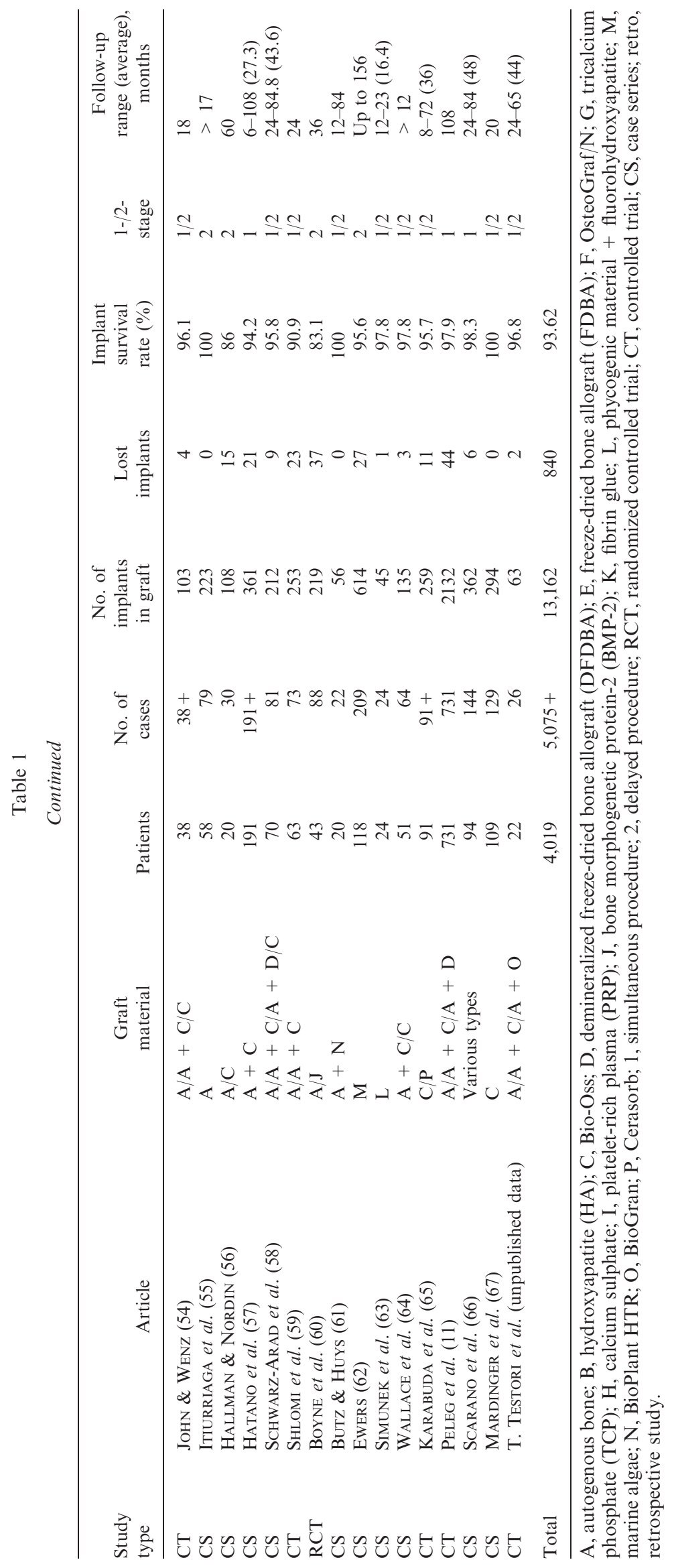


Table 2

Overall implant survival rates according to the graft material and implant surface

\begin{tabular}{|c|c|c|c|c|c|c|c|c|}
\hline Subgroup & $\begin{array}{l}\text { No. of } \\
\text { papers }\end{array}$ & $\begin{array}{l}\text { No. of } \\
\text { patients }\end{array}$ & $\begin{array}{l}\text { No. of } \\
\text { implants }\end{array}$ & $\begin{array}{l}\text { Percentage of } \\
\text { implants }\end{array}$ & $\begin{array}{l}\text { No. of } \\
\text { implant } \\
\text { failures }\end{array}$ & $\begin{array}{l}\text { Implant } \\
\text { survival } \\
\text { rate, \% } \\
\text { (ISR) }\end{array}$ & $\begin{array}{c}\text { ISR with } \\
\text { machined } \\
\text { surfaces, \% } \\
\text { (no. of implants) }\end{array}$ & $\begin{array}{c}\text { ISR with } \\
\text { textured surfaces, } \\
\% \text { (no. of implants) }\end{array}$ \\
\hline Autogenous & 28 & 1,131 & 4,027 & 30.60 & 445 & 88.95 & 84.02 (2365) & 96.74 (1195) \\
\hline$<36$ months & 9 & 337 & 1,231 & 9.35 & 122 & 90.09 & $84.88(767)$ & $98.71(464)$ \\
\hline$>36$ months & 17 & 794 & 2,796 & 21.24 & 323 & 88.45 & $83.60(1598)$ & $95.49(731)$ \\
\hline Combined & 18 & 939 & 2,841 & 21.58 & 150 & 94.72 & $92.57(821)$ & 94.89 (1663) \\
\hline$<36$ months & 12 & 696 & 1,847 & 14.03 & 60 & 96.75 & $94.25(400)$ & 96.97 (1090) \\
\hline$>36$ months & 6 & 232 & 994 & 7.55 & 90 & 90.95 & $90.97(421)$ & $90.92(573)$ \\
\hline Substitutes & 18 & 828 & 2,706 & 20.56 & 106 & 96.08 & 89.62 (106) & 96.46 (2457) \\
\hline$<36$ months & 13 & 628 & 2,096 & 15.92 & 77 & 96.33 & $89.62(106)$ & 98.32 (1847) \\
\hline$>36$ months & 5 & 200 & 610 & 4.63 & 29 & 95.25 & & $90.57(594)$ \\
\hline $\mathrm{NC}$ & 8 & 1,133 & 3,588 & 27.26 & 139 & & & \\
\hline Total & & $4,031 *$ & 13,162 & 100.00 & 840 & & & \\
\hline
\end{tabular}

$\mathrm{NC}$, not classifiable.

*A total of 12 patients in two studies (46, T. Testori, unpublished data) received two different graft materials in their maxillary sinuses in bilateral augmentation procedures.

the degree of roughness, the type of coating or the procedure adopted to roughen the implant surface.

Seven papers (accounting for 525 patients and 1,513 implants) were not classifiable because more than one implant type was utilized for surgery, and separate survival rates for each implant type were not reported (12, $23,32,37,41,50,60)$.

\section{Graft material and implant surface}

Because the introduction of textured surfaces as well as the use of bone substitutes is of a more recent date than the use of machined surfaces and autogenous bone, an analysis was conducted to determine if the proportion of implants would correlate with a given surface and the type of graft material. Figure 3 shows that machined implants have been used much more often in combina-

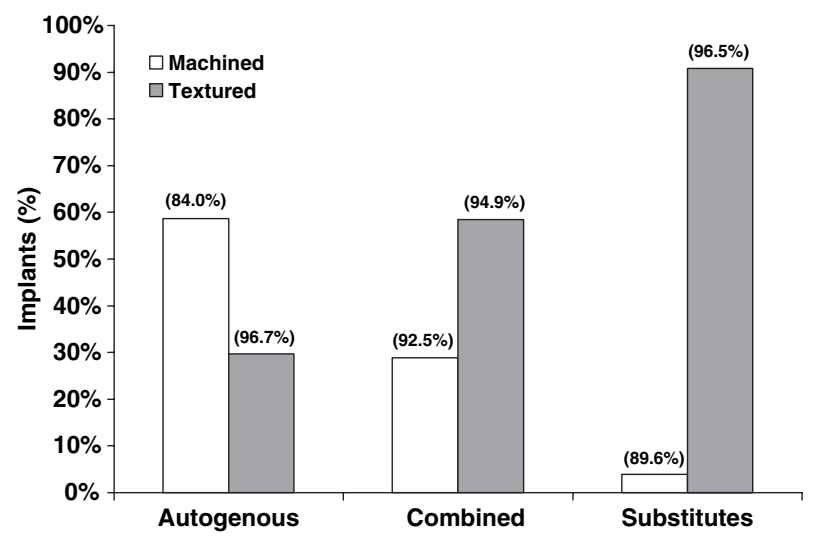

Fig. 3. Proportion of implants with a machined or textured surface, associated with the various types of graft material. The implant survival rate for each subgroup is indicated between parentheses above the bars. The actual number of implants in each subgroup is shown in the last two columns of Table 2 (within parentheses). tion with autogenous bone than with bone substitute materials, where the proportion of implants with an osteoconductive surface is overwhelming. The latter combination was observed, especially in the most recently published articles. These studies also showed the shortest follow-up.

\section{Influence of implant placement timing}

Table 3 shows the overall implant survival rates according to implant placement timing. Data from the two subgroups (simultaneous vs. delayed protocol) were very similar. Twelve papers (accounting for 671 patients and 2,303 implants) were not classifiable because both implant placement timing protocols were used, but separate survival rates were not reported $(23,31,33,45,48$, 59-61, 63-65, 67).

\section{Discussion}

Published data on sinus graft procedures have rapidly increased since the Sinus Consensus Conference of 1996 (68). The overall implant survival rate found in the present review (93.8\%) is higher than that reported by the Sinus Consensus Conference $(90.0 \%$ for implants with at least $3 \mathrm{yr}$ of function) (68) and by more recent systematic reviews that adopted selection criteria similar to those of the present study $(69,70)$. Indeed, most clinical reports published in recent years on this subject reported excellent results, mainly regarding the use of combined grafts or bone substitutes alone, in association with textured surface implants.

\section{Graft material and implant surface}

In this review, it was found that implants inserted in grafts composed of bone substitutes alone, or in grafts composed of a mixture of autogenous bone and 
Table 3

Overall implant survival rates according to implant placement timing

\begin{tabular}{|c|c|c|c|c|c|c|}
\hline Subgroup & $\begin{array}{l}\text { No. of } \\
\text { studies }\end{array}$ & $\begin{array}{l}\text { No. of } \\
\text { patients }\end{array}$ & $\begin{array}{l}\text { No. of } \\
\text { implants }\end{array}$ & $\begin{array}{l}\text { Percentage } \\
\text { of implants }\end{array}$ & $\begin{array}{l}\text { No. of } \\
\text { implant } \\
\text { failures }\end{array}$ & $\begin{array}{l}\text { Implant } \\
\text { survival } \\
\text { rate, \% }\end{array}$ \\
\hline Delayed & 31 & 1,136 & 4,420 & 33.27 & 271 & 93.81 \\
\hline$<36$ months & 19 & 696 & 2,552 & 19.39 & 138 & 94.59 \\
\hline$>36$ months & 12 & 430 & 1,827 & 13.88 & 133 & 92.72 \\
\hline Simultaneous & 36 & 2,223 & 6,480 & 49.23 & 334 & 94.85 \\
\hline$<36$ months & 18 & 771 & 2,074 & 15.76 & 119 & 94.26 \\
\hline$>36$ months & 18 & 1,452 & 4,406 & 33.48 & 215 & 95.12 \\
\hline $\mathrm{NC}$ & 12 & 671 & 2,303 & 17.50 & 235 & \\
\hline Total & & $4,020^{*}$ & 13,162 & 100.00 & 840 & \\
\hline
\end{tabular}

NC, not classifiable.

*One patient in the study by T. Testori (unpublished data) underwent two separate sinus augmentation procedures: in one case the simultaneous protocol was adopted; in the other case the delayed protocol was adopted.

substitutes, may achieve higher survival rates than implants associated with the use of autogenous bone (Table 2). However, it can be misleading to state that combined grafts or bone substitutes per se produce better results than $100 \%$ autogenous bone.

The superiority of a given material over another must be assessed by means of RCTs, whose number in the pertinent scientific literature is still too scarce to draw definitive conclusions.

Furthermore, the effect of the implant surface must be taken into consideration. In the present review, it was found that over $90 \%$ of implants used in association with bone substitutes had a textured surface, while implants used with autogenous bone were mostly machined (about $60 \%$, as shown in Fig. 3). The survival rate for implants with a textured surface was strikingly constant (between 94.9\% and 96.7\%) regardless of the graft material with which they were associated. On the other hand, the outcome of implants with a machined surface was inferior compared to implants with a textured surface, in any type of graft material analyzed (especially for autogenous bone, Table 2). Similar differences in performance between the two types of surface were also reported previously $(69,70)$. This finding is in line with other recent studies that showed the superiority of rough-surfaced implants over smooth-surfaced implants, especially when placed in poor-quality bone or in highrisk patients, such as smokers $(7,71)$ and those with uncontrolled diabetes (72).

Although in good quality bone the success of the implant does not strictly depend on the implant surface, in aged patients (where the posterior maxilla often shows severe osseous atrophy) the use of textured surfaces may positively affect the outcome of implant treatment. In addition, the discomfort of being hospitalized for an extra-oral harvesting procedure under general anaesthesia, increasing the morbidity of the intervention, may promote the use of combined grafts or bone substitutes alone in association with implants having an osteoconductive surface, in order to overcome these limitations.

\section{Influence of implant placement timing}

This review also found that the implant survival rate is not dependent on the use of either a 'simultaneous' or a 'delayed' protocol for implant placement in a sinus floor augmentation procedure. Similar implant survival rates were reported with both techniques, which is in agreement with previous studies (68-70). The amount of residual crestal bone in the posterior maxilla, as it relates to achieving primary implant stability, is a primary factor used by the clinician in choosing a simultaneous over a delayed implant placement. If the residual bone is sufficient to provide implants with adequate 'primary' stability, the simultaneous protocol can be recommended and implants may be placed at the same time of grafting. On the contrary, for cases where residual crestal bone height is extremely reduced (so as not to provide stability to implants) a delayed protocol is recommended. In the latter case, some authors propose the use of a combined graft with an autogenous component, to improve the osteoinductive and osteogenic features of the graft $(23,73)$.

\section{Influence of the surgical technique}

Another variable that may influence treatment outcome is the surgical approach to grafting the maxillary sinus. The lateral swing door technique of TATUM (1) is now the most commonly used and best-documented surgical intervention for increasing alveolar bone height prior to placement of endosseous implants in the posterior maxilla. Other procedures, such as the osteotome sinus elevation technique, were summarized in recent systematic reviews $(70,74)$ and showed quite promising results (implant success range 88.6-100\%). However, clinical reports concerning other techniques to approach the maxillary sinus are still too scarce to allow a statistically adequate analysis on their efficacy. For this reason, only studies where the lateral approach technique was performed were considered in the present analysis. 


\section{Limitations of the review}

Because of great variability in study design, inclusion and exclusion criteria, patient age and gender, smoking habits, implant types (surface, shape, length, and width), ranges in follow-up, use or non-use of a membrane to cover the graft, and amount of residual bone height between the sinus floor and alveolar crest, a direct comparison of published reports was impossible. This situation highlights the difficulties encountered when attempting to draw conclusions from non-controlled studies as a result of the presence of many additional confounding variables that may influence the outcome of the sinus graft procedure. As a consequence, it was not possible to isolate all these separate variables in the present review because data reporting was heterogeneous and specific information on each patient was rarely provided.

As a matter of fact, the conclusions of this review are based mainly on the results of studies having a low level of evidence, such as case series or retrospective studies. These types of study design indeed could be appropriate to determine the prognosis of a given treatment, but should not be used when a comparison between treatments (or between materials) has to be made. This poses a strong limitation to the evaluation of the efficacy of any graft material.

In the present review, implant survival was investigated as the main outcome because it is simple to determine, whereas implant success is more valuable but has to be determined using specific criteria. Unfortunately, these criteria were rather heterogeneous among studies that evaluated implant success, and most of the selected studies only assessed implant survival.

\section{Concluding remarks}

Sinus augmentation procedures are highly predictable, with many studies reporting over $95 \%$ success. This type of surgery may be significantly influenced by the choice of graft material and the implant surface micromorphology. Within the limits of this review, the following conclusions can be drawn:(i) Rough-surfaced implants displayed a higher survival rate than smooth-surfaced implants when placed in grafted sinuses and this was independent of graft type. (ii) Similar survival rates were observed between simultaneous and delayed implant placement. (iii) Grafts using bone-substitute materials were as effective as those using particulate autogenous bone, either when used alone or in combination with autogenous bone, for supporting dental implants. However, it must be considered that in most cases bone substitutes were used in association with textured surfaces. (iv) Long-term reports on sinus floor elevation using non-autogenous grafting materials are still scarce, as a result of their relatively recent introduction, compared with the numerous reports on the use of autogenous bone.

Further studies of a high level of evidence are needed to assess the individual performance of the various bone substitutes and to evaluate the influence of other vari- ables, such as the amount of residual crestal bone in the posterior maxilla, the patient's systemic condition, and smoking habits, on the survival of implants placed in the grafted maxillary sinus.

\section{References}

1. TAtum H JR. Maxillary and sinus implant reconstructions. Dent Clin North Am 1986; 30: 207-229.

2. Boyne PJ, JAMES RA. Grafting of the maxillary sinus floor with autogenous marrow and bone. J Oral Surg 1980; 38: 613616.

3. Buser D, Schenk RK, Steinemann S, Fiorellini JP, Fox CH, STICH H. Influence of surface characteristics on bone integration of titanium implants. A histomorphometric study in miniature pigs. J Biomed Material Res 1991; 25: 889-902.

4. Cochran DL, Schenk RK, Lussi A, Higginbottom FL, Buser D. Bone response to unloaded and loaded titanium implants with sandblasted and acid etched surface: a histometric study in the canine mandible. J Biomed Material Res 1998; 40: 1-11.

5. Lazzara R, Testori T, Trisi P, Porter SS, Weinstein RL. A human histologic analysis of Osseotite and machined surface using two-surfaced implants. Int $J$ Periodontics Restorative Dent 1999; 19: 117-129.

6. Khang W, Feldman S, Hawley CE, Gunsolley J. A multicenter study comparing dual acid-etched and machinedsurfaced implants in various bone qualities. J Periodontol 2001; 72: $1384-1390$

7. Kumar A, Jaffin RA, Berman C. The effect of smoking on achieving osseointegration of surface-modified implants: a clinical report. Int J Oral Maxillofac Implants 2002; 17: 816-819.

8. Stach RM, Kohles SS. A meta-analysis examining the clinical survivability of machined-surfaced and Osseotite implants in poor quality bone. Implant Dent 2003; 12: 87-96.

9. Peleg M, Mazor Z, Chaushu G, Garg AK. Sinus floor augmentation with simultaneous implant placement in the severely atrophic maxilla. J Periodontol 1998; 69: 1397-1403.

10. Winter AA, Pollack AS, Odrich RB. Placement of implants in the severely atrophic posterior maxilla using localized management of the sinus floor: a preliminary study. Int J Oral Maxillofac Implants 2002; 17: 687-695.

11. Peleg M, Garg AK, Mazor Z. Predictability of simultaneous implant placement in the severely atrophic posterior maxilla: a 9-year longitudinal experience study of 2132 implants placed into 731 human sinus grafts. Int J Oral Maxillofac Implants 2006; 21: 94-102.

12. Lozada JL, Emanuelli S, James RA, Boskovic M, Lindsted K. Root-form implants placed in subantral grafted sites. J Calif Dent Assoc 1993; 21: 31-35.

13. Keller EE, Eckert SE, Tolman DE. Maxillary antral and nasal one-stage inlay composite bone graft: preliminary report on 30 recipient sites. J Oral Maxillofac Surg 1994; 52: 438-447.

14. Blompvist JE, Alberius P, Isaksson S. Retrospective analysis of one-stage maxillary sinus augmentation with endosseous implants. Int J Oral Maxillofac Implants 1996; 11: 512-521.

15. Hürzeler MB, Kirsch A, Ackermann K-L, Quinones CR. Reconstruction of the severely resorbed maxilla with dental implants in the augmented maxillary sinus: a 5-year clinical investigation. Int J Oral Maxillofac Implants 1996; 11: 466-475.

16. Triplett RG, Schow SR. Autologous bone grafts and endosseous implants: complementary techniques. Int J Oral Maxillofac Surg 1996; 54: 486-494.

17. Wheeler SL, Holmes RE, Calhoun CJ. Six-year clinical and histologic study of sinus-lift grafts. Int J Oral Maxillofac Implants 1996; 11: 26-34.

18. ZinNer ID, SMALl SA. Sinus-lift graft: using the maxillary sinuses to support implants. J Am Dent Ass 1996; 127: 51-57.

19. Block MS, Kent JN. Sinus augmentation for dental implants: the use of autogenous bone. J Oral Maxillofac Surg 1997; 55: 1281-1286. 
20. Daelemans P, Hermans M, Godet F, Malevez C. Autologous bone graft to augment the maxillary sinus in conjunction with immediate endosseous implants: a retrospective study up to 5 years. Int J Periodontics Restorative Dent 1997; 17: 27-39.

21. Block MS, Kent JN, Kallukaran FU, Thunthy K, WeinBERG R. Bone maintenance 5 to 10 years after sinus grafting. J Oral Maxillofac Surg 1998; 56: 706-714.

22. Blompvist JE, Alberius P, Isaksson S. Two-stage maxillary sinus reconstruction with endosseous implants: a prospective study. Int J Oral Maxillofac Implants 1998; 13: 758-766.

23. Froum SJ, Tarnow DP, Wallace SS, Rohrer MD, Cho S-C. Sinus floor elevation using anorganic bovine bone matrix (OsteoGraf/N) with and without autogenous bone: a clinical, histologic, radiographic, and histomorphometric analysis. Part 2 of an ongoing prospective study. Int $J$ Periodontics Restorative Dent 1998; 18: 529-543.

24. Fugazzotto PA, Vlassis J. Long-term success of sinus augmentation using various surgical approaches and grafting materials. Int J Oral Maxillofac Implants 1998; 13: 52-58.

25. Kaptein Mla, de Putter C, de Lange GL, Blijdorp PA. Survival of cylindrical implants in composite grafted Maxillary sinuses. J Oral Maxillofac Surg 1998; 56: 1376-1380.

26. VAN Den Bergh JPA, ten Bruggenkate CM, Krekeler G, TuINZING DB. Sinusfloor elevation and grafting with autogenous iliac crest bone. Clin Oral Implants Res 1998; 9: 429-435.

27. Watzek G, Weber R, Bernhart T, Ulm C, HaAs R. Treatment of patients with extreme maxillary atrophy using sinus floor augmentation and implants: preliminary results. Int J Oral Maxillofac Surg 1998; 27: 428-434.

28. Buchmann R, Khoury F, Faust C, Lange DE. Peri-implant conditions in periodontally compromised patients following maxillary sinus augmentation: a long-term post-therapy trial. Clin Oral Implants Res 1999; 10: 103-110.

29. De Leonardis D, Pecora GE. Augmentation of the maxillary sinus with calcium sulfate: one-year clinical report from a perspective longitudinal study. Int J Oral Maxillofac Implants 1999; 14: 869-878.

30. Johansson B, Wannfors K, Ekenback J, Smedberg J-I, HiRSCH J. Implants and sinus-inlay bone grafts in a 1-stage procedure on severely atrophied maxillae: surgical aspects of a 3-year follow-up study. Int J Oral Maxillofac Implants 1999; 14: 811-818.

31. Keller EE, Tolman DA, Eckert SE. Maxillary antral-nasal inlay autogenous bone graft reconstruction of compromised maxilla: a 12-year retrospective study. Int J Oral Maxillofac Implants 1999; 14: 707-721.

32. Khoury F. Augmentation of the sinus floor with mandibular bone block and simultaneous implantation: a 6-year clinical investigation. Int J Oral Maxillofac Implants 1999; 14: 557-564.

33. Lekholm U, Wannfors K, Isaksson S, Adielsson B. Oral implants in combination with bone grafts. A 3-year retrospective multicenter study using the Brånemark implant system. Int J Oral Maxillofac Surg 1999; 28: 181-187.

34. Peleg M, Mazor Z, Garg AK. Augmentation grafting of the maxillary sinus and simultaneous implant placement in patients with 3 to $5 \mathrm{~mm}$ of residual alveolar bone height. Int J Oral Maxillofac Implants 1999; 14: 549-556.

35. Lorenzoni M, Pertl C, Wegscheider W, Keil C, Penkner K, Polansky R, BRATSCHKO RO. Retrospective analysis of Frialit-2 implants in the augmented sinus. Int $J$ Periodontics Restorative Dent 2000; 20: 255-267.

36. Olson JW, Dent CD, Morris HF, OChi S. Long-term assessment (5 to 71 months) of endosseous dental implants placed in the augmented maxillary sinus. Ann Periodontol 2000; 5: $152-156$

37. Tarnow DP, Wallace SS, Froum SJ, Rohrer MD, Cho S-C. Histologic and clinical comparison of bilateral sinus floor elevations with and without barrier membrane placement in 12 patients: part 3 of an ongoing prospective study. Int J Periodontics Restorative Dent 2000; 20: 117-125.

38. Van Den Bergh JPA, ten Bruggenkate CM, Krekeler G, TuinzING DB. Maxillary sinusfloor elevation and grafting with human demineralized freeze dried bone. Clin Oral Implants Res 2000; 11: 487-493.
39. Wannfors K, Johansson B, Hallman M, Strandkvist T. A prospective randomized study of 1- and 2-stage sinus inlay bone grafts: 1-year follow-up. Int J Oral Maxillofac Implants 2000; 15: $625-632$.

40. Bahat O, FontAnessi RV. Efficacy of implant placement after bone grafting for three-dimensional reconstruction of the posterior jaw. Int J Periodontics Restorative Dent 2001; 21: 221-231.

41. Geurs NC, Wang I-C, Shulman LB, Jeffcoat MK. Retrospective radiographic analysis of sinus graft and implant placement procedures from the Academy of Osseointegration Consensus Conference on sinus graft. Int $J$ Periodontics Restorative Dent 2001; 21: 517-523.

42. Kahnberg K-E, Ekestubbe A, Gröndahl K, Nilsson P, Hirsch J-M. Sinus lifting procedure. I. One-stage surgery with bone transplant and implants. Clin Oral Implants Res 2001; 12: 479-487.

43. Raghoebar GM, Timmenga NM, Reintsema H, Stegenga B, VISSINK A. Maxillary bone grafting for insertion of endosseous implants: results after 12-124 months. Clin Oral Implants Res 2001; 12: 279-286.

44. Tawil G, Mawla M. Sinus floor elevation using a bovine bone mineral (Bio-Oss) with or without the concomitant use of a bilayered collagen barrier (Bio-Gide): a clinical report of immediate and delayed implant placement. Int J Oral Maxillofac Implants 2001; 16: 713-721.

45. Becktor JP, Eckert SE, Isaksson S, Keller E. The influence of mandibular dentition on implant failures in bone-grafted edentulous maxillae. Int J Oral Maxillofac Implants 2002; 17: 69-77.

46. Hallman M, Hedin M, Sennerby L, Lundgren S. A prospective 1-year clinical and radiographic study of implants placed after maxillary sinus floor augmentation with bovine hydroxyapatite and autogenous bone. J Oral Maxillofac Surg 2002; 60: 277-284.

47. Engelke W, Schwarzwäller W, Behnsen A, Jacobs HG Subantroscopic laterobasal sinus floor augmentation (SALSA): an up-to-5-year clinical study. Int J Oral Maxillofac Implants 2003; 18: 135-143.

48. McCarthy C, Patel RR, Wragg PF, Brook IM. Sinus augmentation bone grafts for the provision of dental implants: report of clinical outcome. Int J Oral Maxillofac Implants 2003; 18: 377-382.

49. Philippart P, Brasseur M, Hoyaux D, Pochet R. Human recombinant tissue factor, platelet-rich plasma, and tetracycline induce a high-quality human bone graft: a 5 -year survey. Int $J$ Oral Maxillofac Implants 2003; 18: 411-416.

50. Rodriguez A, Anastassov GE, Lee H, Buchbinder D, WETTAN H. Maxillary sinus augmentation with deproteinated bovune bone and platelet rich plasma with simultaneous insertion of endosseous implants. J Oral Maxillofacial Surg 2003; 61: 157-163.

51. Stricker A, Voss PJ, Gutwald R, Schramm A, Schmelzeisen R. Maxillary sinus floor augmentation with autogenous bone grafts to enable placement of SLA-surfaced implants: preliminary results after $15-40$ months. Clin Oral Implants Research 2003; 14: 207-212.

52. Valentini P, ABensur D. Maxillary sinus grafting with anorganic bovine bone: a clinical report of long-term results. Int $J$ Oral Maxillofac Implants 2003; 18: 556-560.

53. Hallman M, ZetTerqvist L. A 5-year prospective follow-up study of implant-supported fixed prostheses in patients subjected to maxillary sinus floor augmentation with an 80:20 mixture of bovine hydroxyapatite and autogenous bone. Clin Implant Dent Relat Res 2004; 6: 82-89.

54. JoHN H-D, Wenz B. Histomorphometric analysis of natural bone mineral for maxillary sinus augmentation. Int J Oral Maxillofac Implants 2004; 19: 199-207.

55. ItiurriagA MTM, Ruiz CC. Maxillary sinus reconstruction with calvarium bone grafts and endosseous implants. Int J Oral Maxillofac Surg 2004; 62: 344-347.

56. Hallman M, Nordin T. Sinus floor augmentation with bovine hydroxyapatite mixed with fibrin glue and later placement of nonsubmerged implants: a retrospective study in 50 patients. Int J Oral Maxillofac Implants 2004; 19: 222-227. 
57. Hatano N, Shimizu Y, Ooya K. A clinical long-term radiographic evaluation of graft height changes after maxillary sinus floor augmentatin with a 2:1 autogenous bone/xenograft mixture and simultaneous placement of dental implants. Clin Oral Implants Res 2004; 15: 339-345.

58. Schwarz-Arad D, Herzberg R, Dolev E. The prevalence of surgical complications of the sinus graft procedure and their impact on implant survival. J Periodontol 2004; 75: 511-516.

59. Shlomi B, Horowitz I, Kahn A, Dobriyan A, Chaushu G The effect of sinus membrane perforation and repair with Lambone on the outcome of maxillary sinus floor augmentation: a radiographic assessment. Int J Oral Maxillofac Implants 2004; 19: 559-562.

60. Boyne PJ, Lilly LC, Marx RE et al. De novo bone induction by recombinant human bone morphogenetic protein-2 (rhBMP-2) in maxillary sinus floor augmentation. $J$ Oral Maxillofac Surg 2005; 63: 1693-1707.

61. Butz SJ, HuYS LW. Long-term success of sinus augmentation using a synthetic alloplast: a 20 patients, 7 years clinical report. Implant Dent 2005; 14: 36-42.

62. EwERS R. Maxilla sinus grafting with marine algae derived bone forming material: a clinical report of long-term results. J Oral Maxillofac Surg 2005; 63: 1712-1723.

63. Simunek A, Cierny M, Kopecka D, Kohout A, Bukac J, VAHALOVA D. The sinus lift with phycogenic bone substitute. A histomorphometric study. Clin Oral Implants Res 2005; 16: 342-348.

64. Wallace SS, Froum SJ, Cho SC, Elian N, Monteiro D, Kim BS, TARNOW DP. Sinus augmentation utilizing anorganic bovine bone (Bio-Oss) with absorbable and nonabsorbable membranes placed over the lateral window: histomorphometric and clinical analyses. Int J Periodontics Restorative Dent 2005; 25: 551-559.

65. Karabuda C, Arisan V, Hakan O. Effects of sinus membrane perforations on the success of dental implants placed in the augmented sinus. J Periodontol 2006; 77: 1991-1997.
66. Scarano A, Degidi M, Iezzi G, Pecora G, Piattelli M, Orsini G, Caputi S, Perrotti V, Mangano C, Piattelli A. Maxillary sinus augmentation with different biomaterials: a comparative histologic and histomorphometric study in man. Implant Dent 2006; 15: 197-207.

67. Mardinger O, Manor I, Mijiritsky E, Hirshberg A. Maxillary sinus augmentation in the presence of antral pseudocyst: a clinical approach. Oral Surg Oral Med Oral Pathol Oral Radiol Endod 2007; 103: 180-184.

68. Jensen OT, Shulman LB, Block MS, Iacono VJ. Report of the Sinus Consensus Conference of 1996. Int J Oral Maxillofac Implants 1998; 13(Suppl): 11-32.

69. Wallace SS, Froum SJ. Effect of maxillary sinus augmentation on the survival of endosseous dental implants as compared to the survival of implants placed in the non-grafted posterior maxilla: an evidence-based literature review. Ann Periodontol 2003; 8: 328-343.

70. Del Fabbro M, Testori T, Francetti L, Weinstein RL. Systematic review of survival rates for implants placed in grafted maxillary sinus. Int $J$ Periodontics Restorative Dent 2004; 24: 565-577

71. Bain CA, Weng D, Meltzer A, Kohles SS, Stach RM. A meta-analysis evaluating the risk for implant failure in patients who smoke. Compend Contin Educ Dent 2002; 23: 695-699, 702, 704 passim; quiz 708 .

72. Fiorellini J, Chen PK, Nevins M, Nevins ML. A retrospective study of dental implants in diabetic patients. Int $J$ Periodontics Restorative Dent 2000; 20: 367-373.

73. Valentini P, Abensur D, Wenz B, Peetz M, Schenk R. Sinus grafting with porous bone mineral (Bio-Oss) for implant placement: a 5-year study on 15 patients. Int $J$ Periodontics Restorative Dent 2000; 20: 245-253.

74. Emmerich D, Att W, Stappert C. Sinus floor elevation using osteotomes: a systematic review and meta-analysis. J Periodontol 2005; 76: 1237-1251. 